\title{
Programa de Excelência em Gestão: o caso da Frísia cooperativa agroindustrial
}

\author{
Management Development Program: the case of Frísia cooperativa agroindustrial
}

\begin{abstract}
Resumo
Este estudo de caso aborda a aplicação do Programa de Excelência em Gestão na Frísia Cooperativa Agroindustrial, utilizando a ferramenta do Programa de Desenvolvimento da Gestão das Cooperativas (PDGC), que faz um diagnóstico da governança e da gestão da cooperativa, visando à melhoria contínua a cada ciclo de planejamento, execução, controle e aprendizado. Foram disponibilizados dados pelo SESCOOP-PR, com anuência da cooperativa, referente aos ciclos do PDGC dos anos de 2017 e 2018. Verificou-se que o Îndice SESCOOP de Governança Cooperativista (ISGC) passou de 63,3\% em 2017 para 87,o\% em 2018. E o Índice SESCOOP de Gestão (ISG) passou de 50,3\% em 2017 para 69,4\% em 2018. Para complementar as informações, foi realizada uma entrevista semiestruturada com os agentes de governança da Frísia. A análise dos resultados indica que uma estrutura de governança capaz de integrar as diferentes partes interessadas tem efeitos práticos na efetividade da gestão da cooperativa.
\end{abstract}

Palavras-chave: Governança Cooperativa; Modelo de Gestão; Excelência em Gestão; Cooperativismo.

\begin{abstract}
This case study addresses the application of the Management Excellence Program at Frísia Cooperativa Agroindustrial, using the Cooperative Management Development Program tool (PDGC), which makes a diagnosis of the governance and management structure of the cooperative and aims at continuous improvement in each PDCL (Plan, Do, Check, and Learn) cycle. The data (made available by SESCOOP-PR, with the consent of the cooperative) refers to the PDGC cycles of 2017 and 2018. Results show that the SESCOOP Cooperative Governance Index (ISGC) increased from $63.3 \%$ in 2017 to $87.0 \%$ in 2018 , as well as the SESCOOP Management Index (ISG), which increased from 50.3\% in 2017 to $69.4 \%$ in 2018. In order to get more information, we carried out a semi-structured interview with the governance agents of Frísia. The analysis of the results indicates that a governance structure capable of integrating the different stakeholders has practical effects on the effectiveness of management.
\end{abstract}

Keywords: Cooperative Governance; Management model; Excellence in Management; Cooperativism.

Alfredo Benedito Kugeratski Souza ${ }^{\mathrm{I}}$; Ana Lucia Soares Gonçalves ${ }^{\mathrm{II}}$; Matheus Felipe da Silva ${ }^{\mathrm{III}}$; Rodrigo Gandara Donini ${ }^{\mathrm{IV}} ;$ Sandra de Souza Schmidt ${ }^{\mathrm{V}}$.

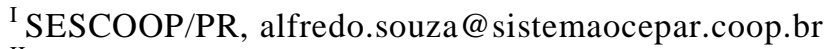

${ }^{\text {II }}$ SESCOOP/PR, ana.lucia@ sistemaocepar.coop.br

III SESCOOP/PR, matheus.silva@ sistemaocepar.coop.br

IV SESCOOP/PR, rodrigo.donini@ sistemaocepar.coop.br

${ }^{v}$ SESCOOP/PR, sandra.schmidt@ sistemaocepar.coop.br 


\section{Introdução}

Este artigo trata da aplicação do Programa de Excelência em Gestão na Frísia Cooperativa Agroindustrial. O objetivo é analisar como uma metodologia de busca contínua pela excelência pode criar incentivos para que uma organização mude suas práticas de gestão e governança, visando um aumento da competitividade e a própria sobrevivência e perenidade da cooperativa no longo prazo. O caso da Frísia é relevante para esta análise pois trata-se de uma empresa que atua em diferentes áreas do setor agropecuário, compete tanto no mercado nacional quanto no internacional, possui faturamento bilionário, além de ser a cooperativa mais antiga do Paraná e a segunda mais antiga do Brasil (FRÍSIA, 2019).

Como se sabe, o desenvolvimento das firmas cooperativas e sua inserção em mercados competitivos globais trazem à tona desafios para a estrutura de governança e gestão. Conforme a Lei 5.764/71, que regula o cooperativismo no Brasil, toda cooperativa já nasce com uma estrutura de governança, formada pela Assembleia Geral, pelo Conselho de Administração e pelo Conselho Fiscal. Além disso, a cooperativa se caracteriza por ser uma sociedade de pessoas que contribuem com bens ou serviços para o exercício de uma atividade econômica comum. Logo, o objetivo não é necessariamente o lucro, mas sim prestar serviços aos associados.

Neste contexto, temos uma situação única em termos de governança e gestão, visto que o mesmo associado pode desempenhar quatro papéis diferentes: dono, gestor, fornecedor e cliente. Cada um desses papéis demanda um tipo de atuação e impõe visões e responsabilidades diferentes sobre o negócio. Logo, questões sobre conflitos de interesse e problemas de agência (JENSEN \& MECKLING, 1976) estão presentes no cotidiano de qualquer cooperativa.

Quando no papel de cliente da cooperativa, o associado deseja o melhor atendimento pelo menor preço possível. Já quando está atuando como fornecedor, ele deseja receber o maior valor possível pela sua produção. Se estiver na figura de gestor, ele deve buscar satisfazer os interesses tanto de fornecedores quanto de clientes, tendo em mente os objetivos e a viabilidade da organização. E no papel de dono, ele se preocupa com o retorno e a sustentabilidade do negócio.

Dada esta condição inerente da firma cooperativa, e os problemas decorrentes dela, é fundamental que os tomadores de decisão busquem soluções. Uma das possibilidades é adotar uma metodologia que promova boas práticas de gestão e governança, que é o caso da Frísia com o Programa de Excelência em Gestão, cuja análise será feita a partir de dados provenientes do Programa de Desenvolvimento da Gestão das Cooperativas (PDGC), além de informações provenientes de uma entrevista semiestruturada com alguns dos principais dirigentes e gestores da cooperativa.

A sequência do artigo apresenta a fundamentação teórica da governança corporativa e cooperativa e discutiremos alguns modelos de gestão para, então, tratar do estudo de caso da Frísia.

\section{Fundamentação Teórica}

A preocupação com a estrutura de governança corporativa das empresas de forma geral - e das cooperativas, em particular - cresce à medida do aumento da relevância dessas firmas no mercado e na sociedade. Isto é, quando as empresas se tornam mais importantes, tanto no mercado quanto na sociedade em que estão inseridas, e exercem influência na vida de mais pessoas, a quantidade de partes interessadas com interesses diversos que estas firmas devem atender cresce. Para conciliar os diferentes interesses, gerar valor e ser sustentável no longo prazo, as empresas devem ter uma estrutura capaz de absorver e processar esta gama de informações de forma efetiva. Em linhas gerais, esta estrutura é a governança corporativa.

Na sequência desta seção, será aprofundada a discussão conceitual de governança corporativa e as particularidades da governança cooperativa. Serão apresentados modelos de gestão e a ferramenta do PDGC (Programa de Desenvolvimento da Gestão das Cooperativas), que é a base para a implementação do Programa de Excelência da Gestão (PEGCOOP). 


\subsection{Governança Corporativa}

Uma empresa tem diversas partes interessadas em constante interação, como os sócios, o conselho de administração, a diretoria executiva, os funcionários, os clientes, os fornecedores, os diferentes entes governamentais e a comunidade de forma geral. A governança é o sistema que permite que uma empresa seja controlada e administrada, através de um conjunto de procedimentos e regras que delimita, organiza e orienta a atuação dessas diferentes partes interessadas, visando a geração de valor econômico e a longevidade da organização (IBGC, 2015).

Esta intrincada rede de relacionamentos impõe uma série de desafios a serem gerenciados no cotidiano das firmas, o que nos leva a discutir a motivação dos agentes econômicos para estabelecer firmas, em primeiro lugar. Ora, se as relações dentro de uma empresa são um obstáculo para a geração de valor, seria mais vantajoso buscar as soluções no mercado, que é regido pelo mecanismo de preços. No entanto, as transações no mercado não são definidas apenas pelo preço dos produtos e serviços. Existe um custo para usar o mecanismo de preços (COASE, 1937).

Com a crescente divisão e especialização do trabalho, torna-se cada vez mais difícil para cada uma das partes envolvidas numa transação ter conhecimento pleno de todas as informações relevantes relacionadas ao trabalho das outras partes. Portanto, para que se chegue num denominador comum para a realização da transação no mercado, é necessário que cada um dos envolvidos busque o máximo possível de informações sobre o que está sendo negociado. Esta busca por informações e a própria negociação em si geram custos (COASE, 1937; NORTH, 1987).

Por isso que, quando se trata do fornecimento de produtos e serviços ao longo do tempo, isto é, com transações repetidas entre as mesmas partes, é mais vantajoso realizar um único contrato grande em substituição a uma série de contratos menores, de forma a reduzir os custos de transação. No entanto, existem dificuldades adicionais para o comprador planejar e especificar as aquisições num ambiente de incertezas, que aumentam à medida que o prazo do contrato aumenta. É neste cenário que o incentivo para estabelecer uma firma, em substituição ao mercado, aumenta (COASE, 1937).

Sendo assim, no contexto da firma, a função de direcionar e alocar os recursos, que antes cabia ao mercado, agora cabe à figura do empreendedor, que deve desempenhar este papel a um custo menor do que aquele que pode ser obtido no mercado (COASE, 1937). Portanto, a firma pode ser entendida como um conjunto de contratos que disciplinam um sistema de relacionamento entre fornecedores e tomadores de produtos e serviços.

Ademais, o reconhecimento do papel das incertezas geradas pela dificuldade de prever o resultado das interações em um ambiente complexo é fundamental para compreender a dinâmica de surgimento das instituições econômicas (contratos, firmas e mercados) e das instituições políticojudiciais (governos, leis e tribunais). São essas instituições que proporcionam estabilidade para os direitos de propriedade (NORTH, 1987; WILLIAMSON, 1985).

Num ambiente de baixa complexidade, as transações são pessoais, realizadas entre indivíduos que possuem grande conhecimento mútuo sobre as características dos seus trabalhos. Desta forma, o custo de transacionar é baixo e a execução dos negócios é garantida pelas normas de conduta da sociedade, mas, por outro lado, o custo de produção de bens e serviços é alto (NORTH, 1987). O aumento da complexidade com a especialização do trabalho leva a trocas impessoais. Porém, sem a presença de instituições que garantam a segurança e execução dos negócios, o nível de especialização tende a se manter baixo. Neste cenário, os custos de transação são altos e os ganhos derivados do comércio são limitados. A necessidade de um terceiro com algum grau de isenção e poder coercitivo para garantir a execução de contratos é que proporciona os incentivos para a criação de uma estrutura estatal. E o desenvolvimento dessa estrutura estatal permitirá a evolução do comércio (NORTH, 1987). Ou seja, é um processo endógeno, no qual as instituições econômicas e as instituições político-judiciais têm influência mútua nos seus respectivos processos de desenvolvimento. Elas evoluem de forma conjunta e interdependente. Em última instância, não observamos a produtividade de uma sociedade industrial complexa na ausência de um estado organizado.

Naturalmente, neste processo, existe também uma crescente sofisticação das práticas de governança e gestão das firmas. No tocante à governança, um dos maiores desafios é mitigar os 
problemas de agência, situação descrita como o conflito de interesse entre o acionista e o executivo contratado, que decorre da assimetria de informação entre as partes e da separação entre propriedade e controle (JENSEN \& MECKLING, 1976).

Tendo em vista que a governança corporativa é um conjunto de regras que visam minimizar os problemas de agência, temos que, o objeto central dos sistemas de governança corporativa não é o de intervir na autonomia das organizações, mas sim equilibrar a competitividade e produtividade da empresa com uma gestão responsável e transparente da mesma (MARQUES, 2007).

Sendo assim, as próximas seções apresentam com mais profundidade as características da governança corporativa e cooperativa.

\subsubsection{Os princípios e os agentes da Governança Corporativa}

De acordo com a $5^{\text {a }}$ edição do Código de Boas Práticas de Governança Corporativa, existem quatro princípios básicos da governança corporativa: Transparência, Equidade, Prestação de Contas (accountability) e Responsabilidade Corporativa, conforme detalha o quadro 1.

Estes princípios estão por trás dos fundamentos e das práticas do Código e aplicam-se a qualquer tipo de organização, independentemente de porte, natureza jurídica ou tipo de controle. Se as melhores práticas podem não ser aplicáveis a todos os casos, os princípios o são, formando o alicerce sobre o qual se desenvolve a boa governança (IBGC, 2015).

Já os agentes de governança são os indivíduos e órgãos envolvidos no sistema de governança, tais como: sócios, administradores, conselheiros fiscais, auditores, conselho de administração, entre outros. Os agentes têm papel relevante no fortalecimento e na disseminação do propósito, dos princípios e dos valores da organização. A liderança e o comprometimento dos administradores e demais executivos são fatores determinantes para a formação de um ambiente ético. (IBGC, 2015)

\section{Quadro 1 - Princípios da Governança Corporativa}

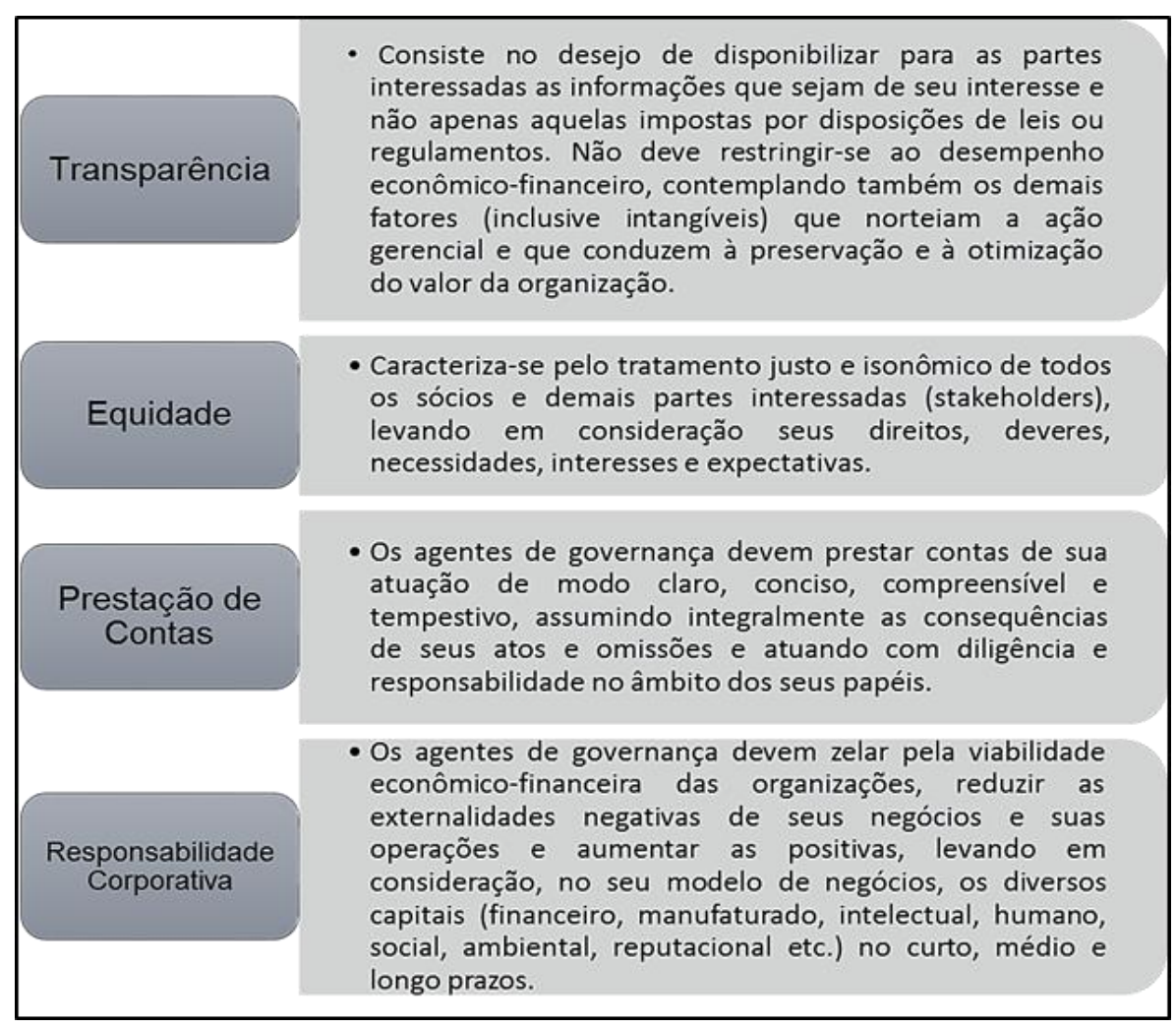

Fonte: IBGC (2015) 


\subsection{Governança em Cooperativas}

As cooperativas são organizações que, em sua constituição, já nascem com uma estrutura de governança. A Lei 5.764/71, que regula as cooperativas brasileiras, estabelece que a sociedade seja administrada por uma Diretoria ou Conselho de Administração, composto exclusivamente de associados eleitos pela Assembleia Geral, com mandato nunca superior a 4 (quatro) anos. Os órgãos de administração podem contratar gerentes técnicos ou comerciais, que não pertençam ao quadro de associados, fixando-lhes as atribuições e salários. Os componentes da Administração e do Conselho fiscal, bem como os liquidantes, equiparam-se aos administradores das sociedades anônimas para efeito de responsabilidade criminal. A lei prevê ainda que a administração da cooperativa seja fiscalizada, assídua e minuciosamente, por um Conselho Fiscal, constituído de 3 (três) membros efetivos e 3 (três) suplentes, todos associados eleitos anualmente pela Assembleia Geral, sendo permitida apenas a reeleição de 1/3 (um terço) dos seus componentes. (BRASIL, 1971)

O cooperativismo é um modelo de negócios pautado pelo empreendedorismo e pela participação democrática, com a proposta de unir pessoas e compartilhar resultados (ZANELLA, 2015). Único caso entre os modelos empresariais, as cooperativas fornecem recursos econômicos sob controle democrático. O movimento cooperativo é universal e oferece milhões de empregos em todo o mundo. As instituições cooperativas criam segurança a longo prazo; são duradouras, sustentáveis e bem-sucedidas. (ACI, 2013)

A Governança Cooperativa, de acordo com Zanella (2015), trata-se de um modelo de direção estratégica, fundamentado nos valores e princípios cooperativistas, que estabelece práticas éticas visando garantir a consecução dos objetivos sociais e assegurar a gestão da cooperativa de modo sustentável em consonância com os interesses dos cooperados.

Desde os seus primórdios, o cooperativismo pauta-se nos valores éticos e sustentáveis da cooperação, bem como em ajuda mútua, responsabilidade, democracia, igualdade, equidade, solidariedade, honestidade, transparência, responsabilidade social e preservação ambiental. Dos valores decorrem os princípios internacionais do cooperativismo, que foram reestruturados ao longo da história e adaptados à realidade social e econômica do mundo atual, consolidando-se em sete, conforme divulgado pela Aliança Cooperativa Internacional - ACI (2013):

o Princípio - Adesão voluntária e livre: As cooperativas são organizações voluntárias, abertas a todas as pessoas aptas a utilizar os seus serviços e assumir as responsabilidades como cooperados, sem discriminações sociais, raciais, políticas, religiosas ou de gênero.

2o Princípio - Gestão democrática e livre: As cooperativas são organizações democráticas, controladas por seus cooperados, que participam ativamente na formulação das suas políticas e na tomada de decisões. Os conselheiros e diretores - eleitos nas assembleias gerais como representantes dos demais cooperados - são responsáveis perante estes.

$3^{\text {o }}$ Princípio - Participação econômica dos cooperados: Os cooperados contribuem equitativamente e controlam democraticamente o capital de suas cooperativas.

4ํㅜㄹincípio - Autonomia e independência: As cooperativas são organizações autônomas, de ajuda mútua, controladas pelos cooperados.

$5^{\circ}$ Princípio - Educação, formação e informação: As cooperativas promovem a educação e a formação de seus cooperados, dos representantes eleitos, dos gerentes e de seus funcionários, de forma que estes possam contribuir eficazmente para o desenvolvimento da cooperativa.

6o Princípio - Intercooperação: Para as cooperativas prestarem melhores serviços a seus cooperados e agregarem força ao movimento cooperativo, devem trabalhar em conjunto com as estruturas locais, regionais, nacionais e internacionais.

$7^{\text {o }}$ Princípio - Interesse pela comunidade: As cooperativas trabalham para o desenvolvimento sustentado das suas comunidades através de políticas aprovadas pelos cooperados.

Os sete princípios do cooperativismo constituem a linha orientadora que rege as cooperativas e formam a base filosófica da doutrina. É por meio dela que os cooperados levam os seus valores à prática (ZANELLA, 2015). Estes princípios também norteiam os princípios da Governança Cooperativa, os quais são tratados no próximo tópico. 


\subsubsection{Os princípios e os agentes da Governança em Cooperativas}

São cinco os princípios da governança cooperativa: Autogestão, Senso de Justiça, Transparência, Educação e Sustentabilidade, apresentados com mais detalhes no quadro 2.

Já os agentes da governança cooperativa são definidos pelo Manual de Boas Práticas de Governança Cooperativa (ZANELLA, 2015) da seguinte forma:

a)Cooperados: pessoas que contribuem para a formação do capital social da cooperativa, e que, ao aderir aos propósitos sociais e preencher as condições estabelecidas no estatuto, tornam-se também beneficiários dos objetivos sociais. São, ao mesmo tempo, proprietários e usuários da sociedade.

b)Assembleia Geral: Órgão soberano da sociedade, com poderes para decidir os negócios relativos ao objeto da sociedade e tomar as resoluções convenientes ao desenvolvimento e defesa desta. Suas deliberações vinculam todos os cooperados, ainda que ausentes ou discordantes.

c)Conselho de Administração/Diretoria: Órgão colegiado, previsto em lei e eleito pela Assembleia Geral, encarregado do processo decisório da cooperativa na esfera de seu direcionamento estratégico. É o principal componente do sistema de governança. Seu papel é ser o elo entre os proprietários (cooperados) e a gestão, orientando e supervisionando a relação desta última com as demais partes interessadas. O Conselho/Diretoria recebe poderes dos cooperados e presta contas a eles por meio de assembleia geral.

d)Conselho Fiscal: Órgão colegiado, eleito pela Assembleia Geral, com poderes estatutários e legais de fiscalizar, assídua e minuciosamente, os atos da administração da cooperativa. É independente dos órgãos de administração, sendo subordinado exclusivamente à Assembleia Geral.

e)Conselho Consultivo: Órgão facultativo, previsto em estatuto e não deliberativo, formado, preferencialmente, por conselheiros independentes ou externos, para melhorar gradualmente a Governança e para dar suporte ao Conselho de Administração/Diretoria em temas relevantes.

f)Comitês Sociais ou Núcleos: Podem ser divididos por região geográfica, produto, especialidade, gênero ou faixa etária e são compostos por cooperados e familiares. Visam à estratificação do quadro social em grupos mais homogêneos, proporcionando maior participação do quadro social para as definições estratégicas.

g)Comitês Técnicos: Órgãos de apoio e suporte ao Conselho de Administração/Diretoria para assuntos que requerem maior profundidade e detalhamento.

h)Auditoria independente: Verificam se as demonstrações econômico-financeiras refletem adequadamente a realidade da cooperativa e apontam melhorias para os controles internos.

i)Gestão Executiva: Conjunto de responsáveis pela execução das diretrizes fixadas pelo Conselho de Administração/Diretoria e deve prestar contas a este órgão. Sua criação deve estar prevista no estatuto social da cooperativa. (ZANELLA, 2015) 
Quadro 2 - Princípios da Governança Cooperativa

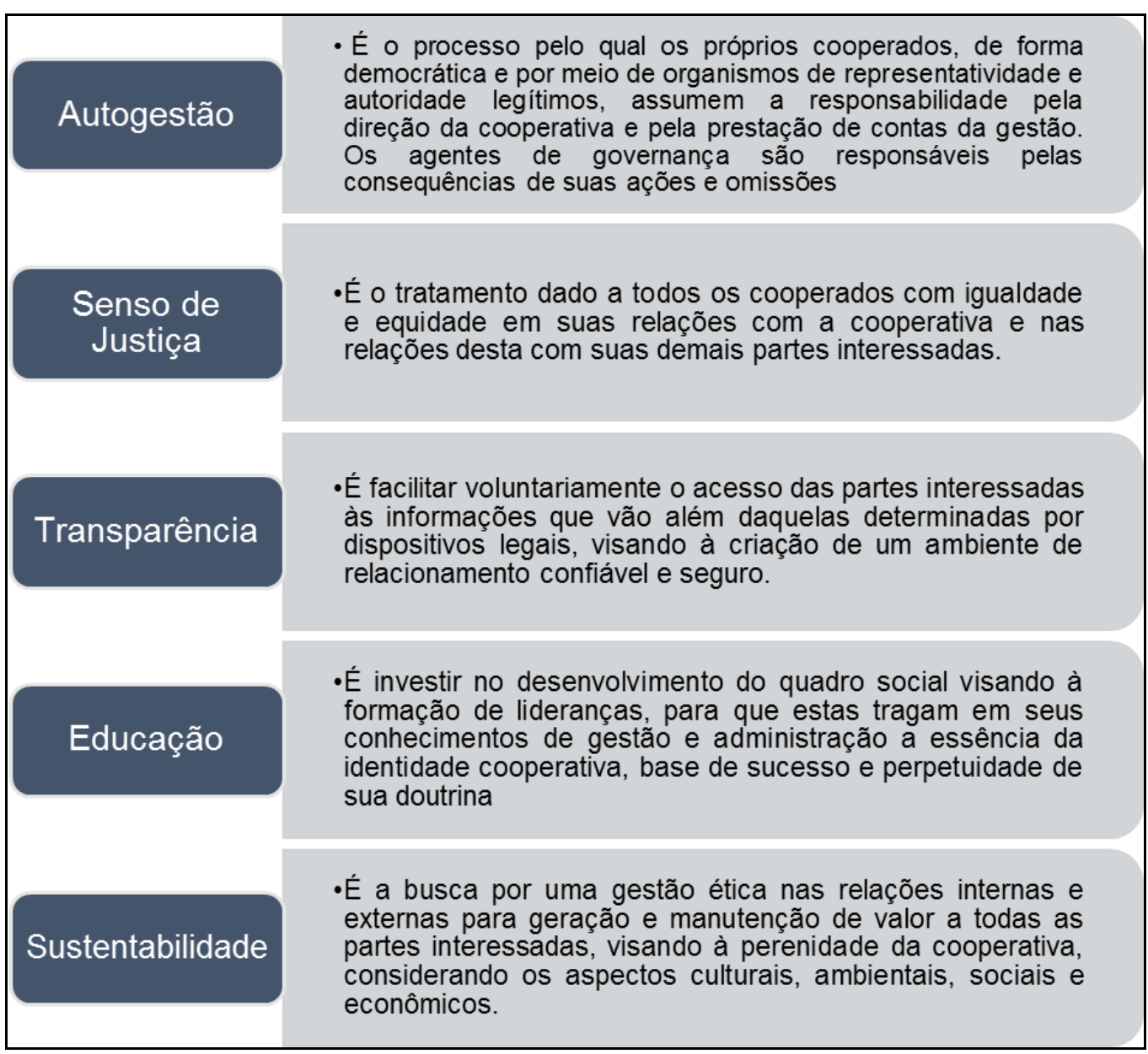

Fonte: Zanella (2015)

Tendo sido apresentados os conceitos de Governança Corporativa e Cooperativa, seus princípios e seus agentes, o próximo tópico vai abordar os modelos de gestão, com seus critérios para avaliação do desempenho das organizações.

\subsection{Modelos de Gestão}

Os Modelos de Gestão, segundo Pagliuso et al., (2010), "são uma representação da realidade que descreve as relações entre diferentes elementos de gestão de uma organização e tem a capacidade de predizer o impacto nas modificações desses elementos".

Os métodos de avaliação de desempenho organizacional são provenientes da Administração da Qualidade Total (Total Quality Manegement - TQM), disseminada a partir do surgimento, em nível mundial, dos Prêmios de Excelência em Gestão. Tais prêmios indicam os requisitos necessários para que as organizações alcancem a excelência e são importantes ferramentas de diagnóstico do desempenho dos sistemas de gestão das organizações. (BOAS \& COSTA, 2011). Assim, as organizações buscam a excelência com base em métodos já consolidados, como por exemplo, os modelos de excelência em gestão preconizados por tais prêmios.

O quadro 3, apresenta um resumo dos principais modelos de gestão, de acordo com Souza (2019): 


\section{Quadro 3 - Os modelos de Gestão no Mundo}

\begin{tabular}{|c|c|c|}
\hline MODELO & DESCRIÇÃO & FATORES \\
\hline $\begin{array}{l}\text { Modelo } \\
\text { Americano } \\
\text { Malcolm } \\
\text { Baldrige }\end{array}$ & $\begin{array}{l}\text { Malcolm Baldrige foi um defensor da gestão da qualidade como uma } \\
\text { chave para a prosperidade e a sustentabilidade dos EUA. Com sua } \\
\text { morte em acidente em 1987, o Congresso nomeou o Prêmio Malcolm } \\
\text { Baldrige National Quality Improvement Act, em reconhecimento de } \\
\text { suas contribuições, com objetivo de melhorar a competitividade das } \\
\text { empresas dos EUA. O Baldrige busca capacitar a organização para } \\
\text { alcançar seus objetivos, melhorar resultados, de modo a tornar a } \\
\text { organização mais competitiva. Por meio de perguntas, que compõem } \\
\text { os Critérios de Excelência de Desempenho, o modelo provoca a } \\
\text { empresa a avaliar se está, e como está, realizando o que é } \\
\text { importante de acordo com sua estratégia. As questões do modelo } \\
\text { são divididas em sete temas, tidos como críticos no gerenciamento e } \\
\text { desempenho de qualquer empresa. }\end{array}$ & $\begin{array}{l}\text { Liderança, Estratégia, } \\
\text { Clientes, Medição, } \\
\text { Análise e Gestão do } \\
\text { Conhecimento, Força de } \\
\text { Trabalho, Operações e } \\
\text { Resultados. }\end{array}$ \\
\hline $\begin{array}{c}\text { Modelo } \\
\text { Europeu } \\
\text { EFQM } \\
\text { Excellence } \\
\text { Model }\end{array}$ & $\begin{array}{l}\text { O EFQM é um modelo referencial europeu amplamente conhecido e } \\
\text { pode ser aplicado para aquelas organizações que buscam a } \\
\text { excelência por meio da adoção dos fundamentos TQM - Total Quality } \\
\text { Management. O Prêmio Europeu de Qualidade (European Quality } \\
\text { Award - EQA) foi oficialmente lançado em 1991, com o propósito } \\
\text { principal de apoiar, encorajar e reconhecer o desenvolvimento efetivo } \\
\text { da gestão da qualidade total (TQM) das empresas Europeias. Seus } \\
\text { critérios dividem-se em habilitadores e resultados. Os habilitadores } \\
\text { de melhoria da qualidade incluem as seguintes categorias: Liderança, } \\
\text { Gestão de Pessoas, Políticas e Estratégia, Recursos e Processos. } \\
\text { Para o EFQM a efetiva implementação dos habilitadores tem impacto } \\
\text { na dimensão resultados, que são compostos pelas seguintes } \\
\text { categorias: Satisfação das Pessoas, Satisfação dos Clientes, Impacto } \\
\text { na Sociedade e Resultados nos Negócios. }\end{array}$ & $\begin{array}{c}\text { Habilitadores Liderança, } \\
\text { Gestão de Pessoas, } \\
\text { Políticas e Estratégia, } \\
\text { Recursos e Processos. } \\
\text { Resultados: Satisfação } \\
\text { das Pessoas, Satisfação } \\
\text { dos Clientes, Impacto na } \\
\text { Sociedade e Resultados } \\
\text { nos Negócios. }\end{array}$ \\
\hline $\begin{array}{l}\text { Modelo TQM } \\
\text { - Total } \\
\text { Quality } \\
\text { Management } \\
\text { (Gestão da } \\
\text { Qualidade } \\
\text { Total) }\end{array}$ & $\begin{array}{c}\text { O TQM dá constante ênfase na satisfação do cliente de modo a } \\
\text { garantir a cultura da qualidade, utilizando o conceito de melhoria } \\
\text { contínua, tornando-se referência e influenciando instrumentos de } \\
\text { mensuração de desempenho e melhoria de resultados. A Gestão da } \\
\text { Qualidade Total cresceu como movimento das empresas em busca } \\
\text { da gestão efetiva. Este modelo de gestão apresenta uma literatura } \\
\text { vasta e é tido como uma filosofia que avança por meio das } \\
\text { necessidades práticas das empresas. }\end{array}$ & $\begin{array}{c}\text { Ambiente, Tamanho da } \\
\text { Organização, Questões } \\
\text { Culturais, Mudanças } \\
\text { Tecnológicas, entre } \\
\text { outras. }\end{array}$ \\
\hline $\begin{array}{l}\text { Modelo } \\
\text { Deming } \\
\text { Prize do } \\
\text { Japão }\end{array}$ & $\begin{array}{l}\text { Estabelecido pela JUSE - Japanese Union of Scientists and Engineers } \\
\text { (União Japonesa de Cientistas e Engenheiros) em 1951, é o prêmio } \\
\text { mais antigo entre todos no mundo. Seu intuito inicial era contribuir com } \\
\text { a reestruturação da nação japonesa, por meio da difusão da qualidade, } \\
\text { reconhecendo melhorias de desempenho provenientes do uso da } \\
\text { metodologia CWQC - Company-Wide Quality Control (Controle de } \\
\text { Qualidade da Empresa). O Deming Application Prize faz uso de um } \\
\text { check list de verificação de dez fatores principais, com especialistas } \\
\text { responsáveis por julgar o desempenho utilizando estes fatores como } \\
\text { requisitos referenciais, os quais são ponderados. }\end{array}$ & $\begin{array}{l}\text { Políticas, Organização, } \\
\text { Informação, } \\
\text { Padronização, Recursos } \\
\text { Humanos, Garantia de } \\
\text { Qualidade, Manutenção, } \\
\text { Melhoria, Efeitos e } \\
\text { Planos Futuros }\end{array}$ \\
\hline $\begin{array}{l}\text { Modelo } \\
\text { Brasileiro } \\
\text { MEG } 20^{:} \\
\text {edição da } \\
\text { FNQ }\end{array}$ & $\begin{array}{l}\text { Em } 11 \text { de outubro de } 1991 \text { a Fundação para o Prêmio Nacional da } \\
\text { Qualidade (FNPQ), atualmente FNQ, instituiu o PNQ - Prêmio } \\
\text { Nacional da Qualidade, que teve seu primeiro ciclo em 1992. O } \\
\text { modelo adotou integralmente os critérios do Prêmio Malcolm } \\
\text { Baldrige, dos EUA, por estabelecer seus critérios de avaliação com } \\
\text { base nos referenciais de excelência da Gestão da Qualidade Total } \\
\text { (TQM), sem prescrever metodologia de implementação e com ampla } \\
\text { bibliografia para aplicação. Nos anos seguintes a FNPQ estreitou } \\
\text { relacionamento com os dirigentes do prêmio norte-americano e com } \\
\text { os realizadores do EQFM (Prêmio Europeu). }\end{array}$ & $\begin{array}{l}\text { Liderança, Estratégias e } \\
\text { Planos, Pessoas, } \\
\text { Processos, Clientes, } \\
\text { Sociedade, Resultados e } \\
\text { Informações e } \\
\text { Conhecimento }\end{array}$ \\
\hline
\end{tabular}

Fonte: Os autores, adaptado de Souza (2019)

O Modelo de Excelência da Gestão ${ }^{\circledR}$ (MEG) da Fundação Nacional da Qualidade (FNQ), é o referencial brasileiro utilizado para promover a melhoria da qualidade da gestão e o aumento da competitividade das organizações. A partir do $\mathrm{MEG}^{\circledast}$ é que nasceu o PDGC (2019), Programa de Desenvolvimento da Gestão das Cooperativas, o qual é detalhado no tópico a seguir. 


\subsection{O Programa de Desenvolvimento da Gestão das Cooperativas - PDGC}

O Programa de Desenvolvimento da Gestão das Cooperativas (PDGC) é um dos programas do SESCOOP voltados ao desenvolvimento da autogestão das cooperativas. Seu objetivo principal é promover a adoção de boas práticas de gestão e de governança pelas cooperativas. Aplicado por meio de instrumento de avaliação, em ciclos anuais, o PDGC faz um diagnóstico objetivo da governança e da gestão da cooperativa, visando à melhoria contínua a cada ciclo de planejamento, execução, controle e aprendizado. (SESCOOP, 2019a)

O Instrumento de Avaliação é dividido em dois questionários (PDGC, 2019):

a) Questionário de Governança: baseado no Manual de Boas Práticas de Governança Cooperativa do Sistema OCB, que é um modelo de direção estratégica, fundamentado nos valores e princípios cooperativistas.

b) Questionário de Gestão: avalia a gestão da cooperativa com base no Modelo de Excelência da Gestão ${ }^{\circledast}$ (MEG) da Fundação Nacional da Qualidade (FNQ), referencial utilizado para promover a melhoria da qualidade da gestão e o aumento da competitividade das organizações.

\subsection{1 Índices para acompanhamento e monitoramento do PDGC}

Ao preencher os questionários, a cooperativa recebe uma devolutiva, com oportunidades de melhoria, para as quais será possível definir as ações para o desenvolvimento da cooperativa. Na devolutiva também são gerados os índices para acompanhamento e monitoramento da melhoria nos processos da cooperativa:

a) Índice Sescoop de Governança Cooperativista (ISGC): Reflete o desempenho nas questões do questionário de Governança, para os sete critérios: Cooperados, Assembleia Geral, Conselho de Administração/Diretoria, Conselho Fiscal, Gestão Executiva, Comitês e Auditorias e Resultados.

b) Î́ndice Sescoop de Gestão (ISG): Reflete o desempenho nas questões do questionário Gestão, nos oito critérios do MEG: Liderança, Estratégias e Planos, Clientes, Sociedade, Informações e Conhecimento, Pessoas, Processos e Resultados.

Ao participar do PDGC, a cooperativa obtém, entre outros benefícios: o conhecimento do grau de maturidade de suas práticas de governança e gestão; a oportunidade de autoavaliação sobre suas práticas de gestão; relatórios com pontos fortes e oportunidades para melhoria; promoção do aprendizado organizacional; desenvolvimento da visão sistêmica dos dirigentes (SESCOOP, 2019a).

\subsection{O Programa de Excelência da Gestão - PEGCOOP}

A autoavaliação realizada através dos Instrumentos do PDGC é parte de um objetivo maior, que é a busca pela excelência. Este objetivo pode ser perseguido por meio do Programa de Excelência da Gestão - PEGCOOP, que é desenvolvido em quatro fases: Estruturar, Desenvolver, Verificar e Transformar.

Na fase "Estruturar", o objetivo é selecionar as pessoas que serão responsáveis pelo Programa dentro da cooperativa. O primeiro passo é garantir o apoio da alta administração, o chamado Tom da Liderança. A cooperativa deve definir quem será o Patrocinador do Programa e esta pessoa deve ocupar um cargo estratégico, seja no Conselho de Administração ou na Diretoria. O Patrocinador será responsável por evidenciar aos seus pares que o PEGCOOP proporciona ganhos no longo prazo, além de participar na execução do projeto, reunindo-se com o comitê e com o time de excelência periodicamente, a fim de inteirar-se do andamento do processo, definir as prioridades, metas para o ciclo e próximos desafios de gestão.

Em seguida, define-se o Comitê de Excelência, um grupo de líderes de 5 a 20 pessoas, entre Diretores, Assessores, Gerentes e Coordenadores, dependendo do porte da cooperativa e dos níveis hierárquicos. Uma dessas pessoas será o Coordenador da Excelência. Estes líderes vão montar o Time de Excelência para executar os trabalhos do Programa. Todas estas pessoas devem ser capacitadas periodicamente sobre o MEG, para que o trabalho seja o mais produtivo possível.

Na fase "Desenvolver", os Instrumentos do PDGC são usados para fazer a autoavaliação, a chamada fotografia da gestão, que vai guiar os trabalhos. Esta fotografia evidencia as oportunidades 
de melhoria que permitem a elaboração de um plano de ação. O Comitê de Excelência tem o dever de elaborar este plano e executá-lo junto com o Time de Excelência.

$\mathrm{Na}$ fase "Verificar", após a conclusão dos trabalhos delineados no plano de ação, o Patrocinador, o Comitê e o Time de Excelência avaliam as entregas realizadas, preenchem uma nova autoavaliação (para que seja feita a comparação com a fotografia inicial) e decidem sobre a continuidade do Programa.

Por fim, na fase "Transformar", espera-se que a cultura da excelência tenha sido inserida no dia-a-dia da gestão. A transformação da gestão é um processo que acontece enquanto os planos de melhoria são colocados em prática e os processos gerenciais são melhorados. É importante assegurar a continuação do Programa e prosseguir com a busca pela excelência por meio de outras ferramentas de gestão, além de benchmarking com empresas conceituadas, pois a troca de práticas e experiências fortalece o programa e amplia o conhecimento sobre o modelo de excelência.

\section{Estudo de Caso: A Frísia Cooperativa Agroindustrial}

A história da Frísia Cooperativa Agroindustrial começa em 1911 quando as primeiras famílias holandesas se estabeleceram na região dos Campos Gerais. Esses pioneiros, em 1925, criaram uma cooperativa de produção no Brasil, com sete sócios e uma produção leiteira de 700 litros/dia, produzindo manteiga e queijo que eram comercializados em Ponta Grossa, Castro, Curitiba e São Paulo, originando a Sociedade Cooperativa Hollandeza de Lacticínios. Isso coloca a Frísia como a cooperativa mais antiga do estado do Paraná e a segunda do Brasil. Três anos depois, a sociedade deu origem à marca Batavo. A partir de 1943, com a chegada de novos imigrantes, o quadro social da cooperativa se expande, iniciando o processo de introdução da cultura mecanizada e aprimoramento genético na atividade pecuária, com a vinda dos primeiros gados puros da raça holandesa. Em 1954, surgiu a Cooperativa Central de Laticínios do Paraná Ltda e desde então, a Cooperativa focou-se na produção agropecuária, buscando atender ao seu quadro social na comercialização, aquisição de insumos e assistência técnica. Em 1997, a CCLPL transformou-se na Batávia S.A e em 2007 foi totalmente incorporada à Perdigão S.A. No ano de 2011, a cooperativa retornou à industrialização, com a produção dos seus cooperados. Foi inaugurada a construção da Central de Processamento de Leite Frísia e, em 2014, a consolidação dos projetos de intercooperação, alianças estratégicas, com as cooperativas Castrolanda e Capal nas áreas de negócios trigo, leite e suínos com as marcas Herança Holandesa, Colônia Holandesa e Alegra, respectivamente. Em agosto de 2015, a Batavo Cooperativa Agroindustrial mudou sua denominação social para Frísia Cooperativa Agroindustrial, em virtude da venda do nome Batavo para o mercado varejista (FRÍSIA, 2019).

Em 2018 a cooperativa era formada por 837 cooperados, 1.042 funcionários e apresentou faturamento de R \$ 2,6 bilhões e sobras líquidas de R\$97,5 milhões, com atuação na região de centrosul do estado do Paraná e na região de Palmas no estado de Tocantins. O volume de recebimento de produção foi de 476 mil de soja, 106 mil toneladas de milho e 121 mil toneladas de trigo (FRÍSIA, 2019). O ranking Valorıoo, elaborado pelo jornal Valor Econômico, que classifica as 1.ooo maiores empresas do Brasil com base nos seus indicadores econômico-financeiros, coloca a Frísia na $254^{\circ}$ posição geral, sendo a $43^{\underline{a}}$ colocada na região sul e a $16^{\underline{a}}$ maior empresa do setor agropecuário (VALOR ECONÔMICO, 2019).

Por todo o exposto, fica evidente que o caso da Frísia é relevante sob diferentes aspectos. Sob o aspecto econômico, é uma empresa que atua em diferentes áreas do ramo agropecuário, compete tanto no mercado nacional quanto no internacional, possui faturamento bilionário e apresenta resultados financeiros positivos. Em termos sociais, é uma cooperativa integrada com a comunidade da sua região de atuação, o que evidencia também a sua relevância histórica, visto que sua trajetória se confunde com a trajetória dos imigrantes holandeses que ocuparam a região dos Campos Gerais no Paraná, além de ser uma organização fundamental para o cooperativismo paranaense e brasileiro. Ademais, a Frísia também é pioneira dentro do cooperativismo brasileiro na aplicação de uma metodologia de busca contínua pela excelência nas suas práticas de gestão e governança.

Na sequência, serão apresentados e analisados os dados coletados junto à Frísia Cooperativa Agroindustrial. 


\subsection{Metodologia}

Para compreender o processo de implantação e desenvolvimento do Programa de Excelência em Gestão na Frísia, este estudo apresenta duas análises.

A primeira é uma análise qualitativa, tendo como base as informações obtidas com a entrevista semiestruturada realizada no mês de março de 2019 com 03 (três) agentes de governança da Frísia: o Presidente do Conselho de Administração, o Superintendente e o Gestor responsável pelo Programa de Excelência em Gestão da Frísia. A entrevista seguiu o Roteiro Melhores Práticas, disponível nos anexos deste estudo, que é uma adaptação do material que consta no Compêndio de Boas Práticas de Gestão e Governança (SESCOOP, 2019b).

A segunda análise é quantitativa, a partir dos dados levantados pelo Instrumento de Autoavaliação Primeiros Passos para a Excelência (PDGC, 2019). O questionário, anexo a este artigo, é composto por 11 questões de Governança e 45 questões de Gestão, separadas em 8 critérios: Liderança, Estratégias e Planos, Clientes, Sociedade, Informações e Conhecimento, Pessoas, Processos e Resultados.

\subsection{Análise Qualitativa}

A cooperativa caminha para o terceiro ciclo do Programa de Excelência em Gestão e esta foi uma forma de integrar todas as práticas de gestão existentes na cooperativa. Até então existiam práticas em setores separados e, hoje, tudo agora está em uma mesma linguagem. O PEGFrísia contribui para que a cooperativa sincronize as práticas e fale a mesma língua. Também ajuda a cooperativa a fazer um diagnóstico, pois é difícil medir a posição em relação a gestão, esse programa auxilia a dar uma nota, a identificar o pontos de melhoria e isso que é este é o principal ponto da prática, conseguir identificar o que há de melhor, e integrar toda a organização.

O Conselho de Excelência, que foi constituído com os gerentes, superintendência e algumas pessoas chave no processo é multifuncional e todas a gerências têm representatividade e responsabilidades definidas. Essa prática contribui muito com o Programa, pois o conselho auxilia o PEGFrísia a agregar as práticas, tornando a gestão mais integrada. Além disso, o superintendente faz parte da equipe efetiva de implantação do projeto, envolvendo-se ativamente no planejamento e na execução das atividades do Programa.

O Conselho de Administração da cooperativa acompanha o Projeto de implantação do PEGFrísia como Sponsor - patrocinador, tendo conhecimento da execução do projeto e participando dos eventos do planejamento estratégico ou em outros eventos na cooperativa em que o tema é tratado, como por exemplo, na Convenção Anual com todos os colaboradores.

O projeto de implantação do PEGFrísia é estruturado, com cronograma de etapas que contemplam a evolução do Programa desde os "Primeiros Passos" ao nível de maturidade de "Excelência em Gestão", culminando em um objetivo de longo prazo que conflui com as comemorações do Centenário da Cooperativa.

Anualmente, a evolução do programa vem sendo acompanhada respondendo ao questionário do PDGC, o que leva a análises de pontos de melhoria, a partir dos quais são elaborados diversos planos de ações que visam aumentar as pontuações obtidas no questionário. Esses planos de ação são desenvolvidos/construídos pelo Conselho de Excelência da cooperativa, com o apoio técnico da equipe do SESCOOP/PR. Cabe ressaltar que as ações dos planos de melhorias são distribuídas entre os integrantes do Conselho de Excelência.

Dada esta estruturação, é utilizado um sistema de Gestão de Projetos e de Ações que reúne todas as atividades relacionadas tanto ao projeto de Implantação quanto às ações provindas de planos de melhoria do programa. A equipe do projeto, denominada Coachs de Excelência, é constituída pelo superintendente e analistas da gestão da qualidade e faz o acompanhamento semanal das atividades previstas e cadastradas no Sistema de Gestão, junto com integrantes do Conselho de Excelência. Assim, a Superintendência consegue acompanhar com frequência todo o desenvolvimento do Projeto e cumprimento dos Planos estabelecidos.

Um dos principais ganhos do programa é proporcionar a reorganização dessa parte de gestão, onde se muda a situação de uma cooperativa extremamente setorizada e começa a integrar essas 
áreas. Entender que uma área depende da outra e, assim, colocar a cooperativa no caminho da integração. Dessa forma, começou-se a perceber uma relação muito importante entre as áreas, o que fortaleceu a governança. Antes se governava por setor: o setor financeiro, o setor agrícola, o setor pecuário. Porém, observa-se que o setor pecuário depende do setor agrícola, que depende do financeiro, que depende dos resultados de todas as áreas, assim como o administrativo, que precisa ter uma relação total com os outros setores da cooperativa. O programa contribuiu inicialmente trazendo e compartilhando as boas práticas de cada área. $\mathrm{O}$ nível de relacionamento das pessoas por causa do programa também se intensificou e se mantém vivo, pois a cada 3, 4 meses a equipe se reúne para revisar o programa e analisar os avanços e o que ainda precisa ser trabalhado para prosseguir com mais melhorias

O modelo é bastante abrangente e permite que a cooperativa não olhe apenas para o resultado, mas também para os critérios como liderança, pessoas, processos, estratégias: nada fica de fora. Entende-se que ele está muito mais voltado para pessoas e processos do que para os resultados. Observa-se uma autonomia total da equipe do programa, a diretoria não tem interferência nesse processo, apenas de forma estratégica, mas todo o processo está sendo desenvolvido pela equipe. O Presidente não participa diretamente de nenhuma ação, apenas vivencia a jornada. Isso mostra que a diretoria da cooperativa vem evoluindo na questão das pessoas. O comprometimento do time grupo de trabalho - tem melhorado muito e esse time está entendendo que as ações que a cooperativa faz na atividade agrícola, pecuária e financeira são interdependentes e essa noção permite ao grupo ter um olhar cada vez mais amplo do negócio da Frísia, não somente do seu setor.

Com o tempo, a cooperativa tem conseguido formatar esse modelo e isso tem sido feito de forma muito sutil. Não foi imposto, foi estratégico, trazendo pessoas e atuando para que se pudesse capturar um modelo no qual há um grupo muito mais participativo dentro do processo. Este é o maior ganho: o time envolvido tem muito mais garra do que há 5 anos e cada um sabe exatamente qual é o papel que precisa desempenhar. Essa responsabilidade acaba refletindo nos outros setores. Tudo que uma pessoa faz, de alguma forma, é perceptível e estimula o sentimento de que cada ação realizada pelo indivíduo vai refletir em outro setor. Isso faz com que ele se pergunte se suas ações terão impacto positivo ou negativo no seu setor, na sua equipe e na própria cooperativa.

Outro ponto que vem avançando é a Gestão de Riscos. Antes da governança compartilhada, as pessoas assumiam o risco sozinhas, bem como suas consequências. Era uma só pessoa pensando na situação, se fechava o negócio ou não, se assumia o risco ou se deixava as oportunidades passarem. Atualmente, as situações de risco são discutidas entre os diversos setores envolvidos e trazem oportunidades que antes passavam, ampliando as chances de negócios da cooperativa. É importante a integração proporcionada pelo programa, para compartilhar o risco entre os setores.

As principais dificuldades antes da adoção do PEGFrísia estavam relacionadas à setorização da cooperativa, que comprometia a integração dos setores. De qualquer forma, as dificuldades possibilitaram a construção de um modelo mais adequado para tocar o negócio da cooperativa, que vinha em um processo de crescimento e ampliação do negócio. Por isso, a integração tornou-se essencial no processo.

Há um ganho de sinergia. Antes existiam muitas ações isoladas e com a implantação do programa, tudo se tornou mais multifuncional. Um exemplo disso é o Programa Frísia Mais Lean, lançado no setor de leite e depois na suinocultura. O setor agrícola também estava desenvolvendo um Programa Lean próprio. Foi então que se percebeu que esse era um programa de toda a cooperativa, visto que o modelo é o mesmo para todos os setores. Assim foi lançado o Programa Frísia Mais Lean, que está sendo implantado internamente e de forma integrada.

O que também tem melhorado, na percepção dos gestores, são os processos que estão sendo mapeados, principalmente nas áreas de recepção e armazenagem de grãos, ampliando sua eficiência e deixando claro o papel de cada indivíduo no processo. As descrições dos cargos estão sendo redefinidas, ampliando a possibilidade de atuação dentro da cooperativa. Dessa forma, a equipe pode ser tornar mais versátil, assumindo tarefas que a descrição do cargo não permitia.

A motivação para implantação dessa prática surgiu no planejamento estratégico e foi muito incentivada pelo SESCOOP/PR, que promoveu fóruns sobre o tema Excelência em Gestão, dos quais a cooperativa participou. Porém, a inclusão do programa no planejamento estratégico foi que fez o 
projeto deslanchar, com o entendimento de que essa área é estratégica para cooperativa e deveria atuar de forma transversal. O fato de o PEGFrísia fazer parte da carteira de Projetos Estratégicos da Frísia o coloca como um programa prioritário no portfólio da cooperativa.

A Frísia é uma cooperativa das mais tradicionais do Paraná e do Brasil. Ela tinha um modelo com base de produção que contava com uma cooperativa central, detentora da marca Batavo, na qual outras cooperativas inspiraram seus modelos nas décadas de 70 e 8o. Depois, houve um período de estagnação da produção e engessamento da marca, o que limitou o negócio da central, pois tudo o que era produzido pelas cooperativas envolvidas com a central acabava sendo industrializado pela marca Batavo, gerando muitas vezes uma produção maior que a demanda, desagregando o preço em algum ponto da cadeia, o que conduziu a uma dificuldade financeira. Nessa época, houve interferência incisiva da governança, que era composta por produtores e tomavam decisões que influenciavam tanto na indústria, quanto no campo e os interesses particulares começaram a pesar, levando a um conflito que foi o ponto crucial para o fim da central.

Este fato foi um ensinamento muito importante, que culminou na saída da cooperativa da agro industrialização no período de 2008 a 2011. Nessa época, a cooperativa produzia e tentava comercializar a produção no mercado spot, com leite e suínos. Na parte de grãos não houve nenhuma mudança significativa. Foi quando a cooperativa percebeu que estava se tornando refém do processo, principalmente nos produtos de origem pecuária, e isso se tornou uma ameaça. Era necessário agregar valor e manter o produtor fidelizado ao processo da cooperativa. Foi quando o processo de industrialização foi retomado e a cooperativa deu o primeiro passo para a intercooperação.

\subsubsection{Desafios e lições aprendidas}

Em um primeiro momento quebrar as barreiras dos setores foi um dos principais desafios. Era necessário demonstrar que a integração promovida pelo PEGFrísia seria boa para cada um dos participantes do grupo e todas as áreas acabaram se envolvendo. $\mathrm{O}$ andamento do projeto permitiu que eles percebessem as vantagens, tanto individuais, quanto para a cooperativa. $\mathrm{O}$ diagnóstico inicial mostrou de forma clara que existiam pontos de melhoria. Também há o desafio de manter as pessoas engajadas, entendendo que a mudança cultural é necessária, pois ainda há um longo caminho para percorrer. O PEGFrísia é um programa de longo prazo que proporciona um ganho diário, especialmente de eficiência de resultado.

Para a implantação do programa, o importante é ter uma linha de trabalho e dar a devida importância a ele. Também é importante identificar o momento no qual a cooperativa se encontra, para definir o próximo estágio, que tem que ser melhor que o atual. O programa deve promover a evolução da cooperativa, passando por processos cada vez mais organizados. O planejamento estratégico deve ser uma ferramenta para direcionar a cooperativa, e deve ser dinâmico sem nunca esquecer do dono do negócio, que é o cooperado. É ele que deve capturar valor no que tem sido feito pela cooperativa. Por isso é fundamental se questionar: Isso é bom para a cooperativa? E o mais importante: Isso é bom para o cooperado? Todo negócio da cooperativa deve trazer retorno para o cooperado.

Outro aprendizado que o programa proporcionou é que a alta gestão, junto com o conselho, tem que estar muito bem voltada para que as melhorias propostas aconteçam. Caso contrário, se inicia um processo de começar por um setor para testar, ver se dá certo, e isso já é um início errado. Na Frísia, o conselho comprou a ideia de um programa de melhoria sabendo que ele vai promover o crescimento das pessoas e tudo vai convergir para trazer resultados, eficiência e muito mais. Também é importante começar com o "pé no chão" e entender que melhorar é preciso, e isso deve ser feito passo a passo.

No caso do PEGFrísia, o projeto de implantação não teria sido iniciado sem que a Diretoria conhecesse e apoiasse o programa. Nas primeiras etapas do projeto, ele foi apresentado para Comitê de Gestão (composto por Gerentes e Superintendente), Diretoria Executiva, Conselho de Administração e Conselho Fiscal. Nestas apresentações foi possível estabelecer claramente os pontos de dúvidas e receios existentes e foi seguida a metodologia de Gestão de Projetos (PMBoK) para promover a Implantação do Programa de Excelência em Gestão Frísia. 


\subsubsection{Resultados}

O PEGFrísia proporcionou o fortalecimento da cooperativa de uma forma mais integrada e o compartilhamento de boas práticas. Foram implementadas melhorias em várias áreas. O programa começou abrir a mente pra novos modelos de gestão, como por exemplo o lean. O novo ERP também foi uma necessidade identificada. Começa-se a pensar em como se quer a Frísia no futuro, muito mais dinâmica, mais ágil, e percebe-se que se as ferramentas não forem melhoradas não há como fazer isso, pois a informação vai demorar e informação rápida é importante para o futuro da cooperativa.

O trabalho com o ERP é um exemplo muito forte de integração que está correndo bem, no qual a estratégia de implementação foi bem desenhada e mesmo que sejam identificados problemas, eles vão contribuir para melhorar cada vez mais a governança da cooperativa. Nesta situação, verifica-se que a implementação de um sistema de gestão gera impacto na estrutura de governança, pois permite que a assimetria de informação, naturalmente existente entre gestores, colaboradores e conselheiros, seja reduzida. Consequentemente, a redução desta assimetria diminui a possibilidade de que decisões tomadas contemplem os interesses de apenas uma parte dos agentes envolvidos na operação da cooperativa. Isto tende a ter efeito positivo no resultado da firma, visto que os diferentes agentes da governança estão sendo contemplados nos diferentes processos de gestão. Importante ressaltar que esse processo está ocorrendo de forma mais suave devido ao compartilhamento já iniciado com o PEGFrísia, que criou oportunidades para outras pessoas assumirem responsabilidades e identificar talentos dentro da cooperativa.

O PEGFrísia também ajudou a cooperativa a estruturar o programa de remuneração variável, as metas estão cada vez mais ajustadas e a cooperativa conta com uma estrutura formatada para fazer avaliação individual, possibilitando assim a criação de metas individuais mais fortes, promovendo melhor desempenho do time.

Outro ganho bastante expressivo foi relacionado à melhoria dos processos operacionais, que contribuiu para melhor alocação das pessoas, promovendo redução de despesas e melhores resultados. A otimização da estrutura organizacional permite que a cooperativa seja capaz de conciliar e responder de forma mais efetiva aos interesses das diferentes partes interessadas. Isto é, o ganho não está somente na redução de despesas, mas também no aumento da efetividade. São os efeitos secundários gerados por processos operacionais mais ajustados que muitas vezes não são percebidos.

Enfim, o PEGFrísia deu abertura, trouxe oxigenação para a cooperativa com a vinda de profissionais experientes que têm contribuído para aprimorar a governança, trazendo experiência de mercado para dentro da cooperativa. Esses profissionais perceberam a diferença entre trabalhar em empresas do mercado e em uma cooperativa, sentindo que estão em um ambiente amistoso, no qual as pessoas colaboram umas com as outras, tornando o ambiente mais leve e que, no final, o resultado não é de um setor específico, mas do cooperado e da cooperativa como um todo.

\subsection{Análise Quantitativa}

Em 2019, a Frísia está no terceiro ciclo no Programa de Excelência em Gestão, que segue a metodologia anteriormente descrita no item 2.4. No ano de 2017, em seu primeiro ciclo, a cooperativa preencheu o questionário do PDGC no nível de Primeiros Passos. O questionário é composto por 11 questões de Governança e 45 de Gestão, separadas em 8 critérios: Liderança, Estratégias e Planos, Clientes, Sociedade, Informações e Conhecimento, Pessoas, Processos e Resultados. Para visualizar a evolução da cooperativa nos últimos anos, a Tabela 1 apresenta o resultado da cooperativa no ano de 2017: 
Tabela 1 - Resultado da Frísia no ano de 2017 - Questionário Primeiros Passos PDGC

\begin{tabular}{|c|c|c|c|c|c|}
\hline \multirow{2}{*}{ Cooperativa: FRISIA } & \multirow{2}{*}{\multicolumn{2}{|c|}{ Período: }} & \multirow{2}{*}{\multicolumn{3}{|c|}{ Maturidade: }} \\
\hline & & & & & \\
\hline Bloco Governança & Pont. Máx & Pont. \% & Pontos & Lacuna \% & Pts. Perdidos \\
\hline Governança & 100,0 & $63,3 \%$ & 63,3 & $36,7 \%$ & 36,7 \\
\hline Bloco Gestão & Pont. Máx & Pont. \% & Pontos & Lacuna \% & Pts. Perdidos \\
\hline Liderança & 16,0 & $64,4 \%$ & 10,3 & $35,6 \%$ & 5,7 \\
\hline Estratégias & 9,0 & $57,0 \%$ & 5,1 & $43,0 \%$ & 3,9 \\
\hline Clientes & 9,0 & $39,0 \%$ & 3,5 & $61,0 \%$ & 5,5 \\
\hline Sociedade & 6,0 & $75,0 \%$ & 4,5 & $25,0 \%$ & 1,5 \\
\hline Conhecimento & 6,0 & $45,0 \%$ & 2,7 & $55,0 \%$ & 3,3 \\
\hline Pessoas & 9,0 & $67,5 \%$ & 6,1 & $32,5 \%$ & 2,9 \\
\hline Processos & 15,0 & $31,7 \%$ & 4,8 & $68,3 \%$ & 10,3 \\
\hline Resultados & 30,0 & $44,4 \%$ & 13,3 & $55,6 \%$ & 16,7 \\
\hline Desempenho da Gestão & 100,0 & $50,3 \%$ & 50,3 & $49,7 \%$ & 49,7 \\
\hline
\end{tabular}

O resultado do índice de governança $(63,3 \%)$ mostrava que a Frísia precisava evoluir na sua estrutura para atender as diferentes partes interessadas e diminuir a assimetria de informação (JENSEN \& MECKLING, 1976) entre cooperados, gestão e conselhos. Visto que a estrutura de governança reflete diretamente na gestão (ZANELLA, 2015), o resultado do índice de gestão (50,3\%) também evidenciava que existia espaço para melhorias em diferentes áreas.

\section{Gráfico 1 - Lacunas por critérios}

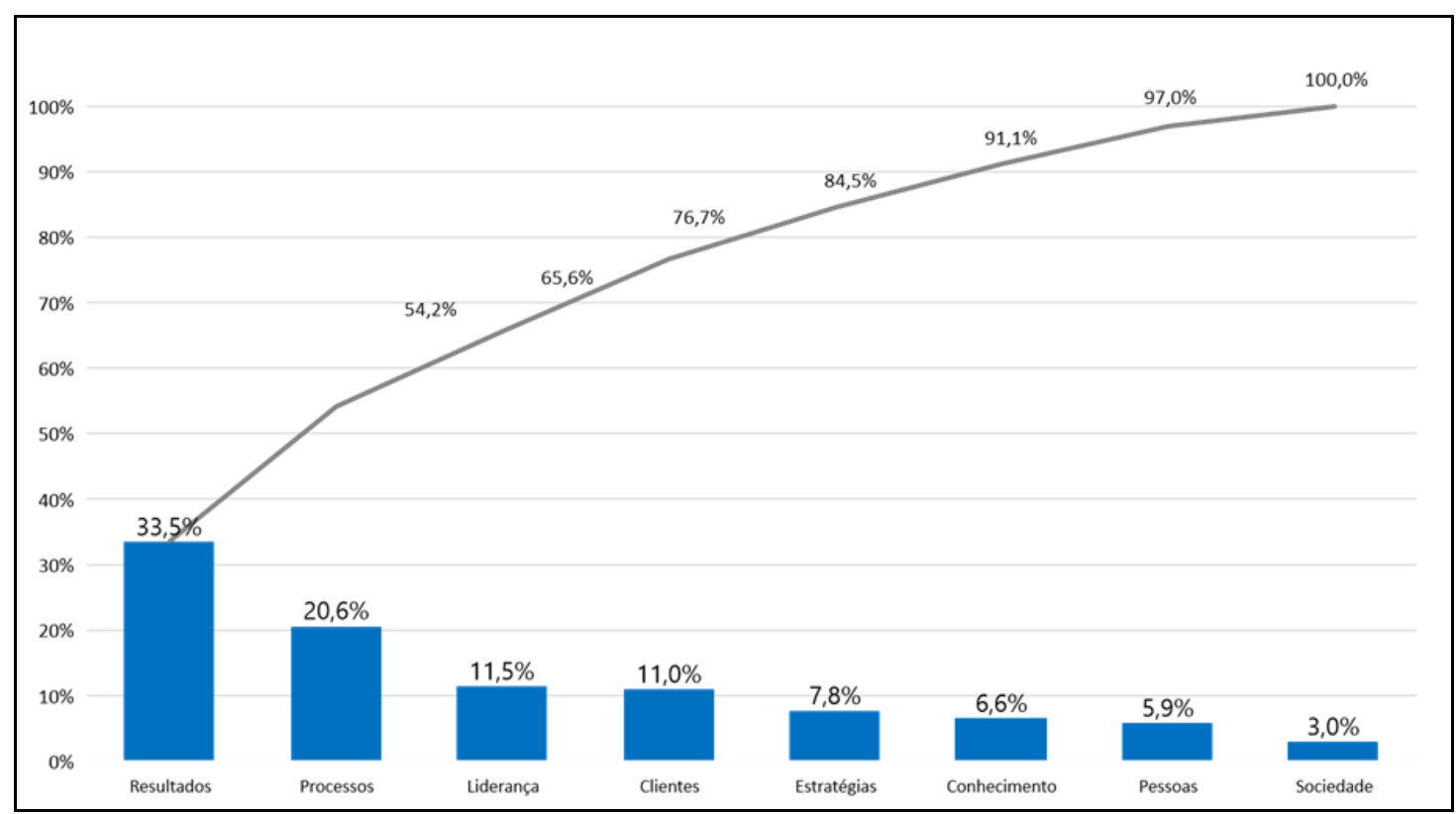

Fonte: SESCOOP/PR (2019)

Conforme ilustrado no Gráfico 1, no caso da Cooperativa Frísia, 76,7\% das oportunidades de melhoria em relação ao questionário dos Primeiros Passos estavam nos critérios Resultados, Processos, Liderança e Clientes. Com base neste diagnóstico, a cooperativa traçou seu plano de ação, visando atacar as principais lacunas para ter um ganho de qualidade significativo num curto espaço de tempo.Sendo assim, em 2018, no segundo ciclo da Frísia no Programa de Excelência em Gestão 
(mas ainda no Questionário dos Primeiros Passos), verificou-se uma evolução em relação ao primeiro ano, como mostra a 2:

Tabela 2 - Resultado da Frísia no ano de 2018 - Questionário Primeiros Passos PDGC

\begin{tabular}{|c|c|c|c|c|c|}
\hline \multirow{2}{*}{ Cooperativa: FRISIA } & \multicolumn{2}{|c|}{ Período: } & \multicolumn{3}{|c|}{ Maturidade: } \\
\hline & & \multicolumn{2}{|c|}{2018} & \multicolumn{2}{|r|}{ PP } \\
\hline Bloco Governança & Pont. Máx & Pont. \% & Pontos & Lacuna \% & Pts. Perdidos \\
\hline Governança & 100,0 & $87,0 \%$ & 87,0 & $13,1 \%$ & 13,1 \\
\hline Bloco Gestão & Pont. Máx & Pont. \% & Pontos & Lacuna \% & Pts. Perdidos \\
\hline Liderança & 16,0 & $87,5 \%$ & 14,0 & $12,5 \%$ & 2,0 \\
\hline Estratégias & 9,0 & $75,0 \%$ & 6,8 & $25,0 \%$ & 2,3 \\
\hline Clientes & 9,0 & $48,0 \%$ & 4,3 & $52,0 \%$ & 4,7 \\
\hline Sociedade & 6,0 & $75,0 \%$ & 4,5 & $25,0 \%$ & 1,5 \\
\hline Conhecimento & 6,0 & $91,7 \%$ & 5,5 & $8,3 \%$ & 0,5 \\
\hline Pessoas & 9,0 & $84,2 \%$ & 7,6 & $15,8 \%$ & 1,4 \\
\hline Processos & 15,0 & $60,8 \%$ & 9,1 & $39,2 \%$ & 5,9 \\
\hline Resultados & 30,0 & $58,8 \%$ & 17,6 & $41,2 \%$ & 12,4 \\
\hline Desempenho da Gestão & 100,0 & $69,4 \%$ & 69,4 & $30,6 \%$ & 30,6 \\
\hline
\end{tabular}

Fonte: SESCOOP/PR (2019)

Gráfico 2 - Desempenho Bloco de Gestão 2017 e 2018

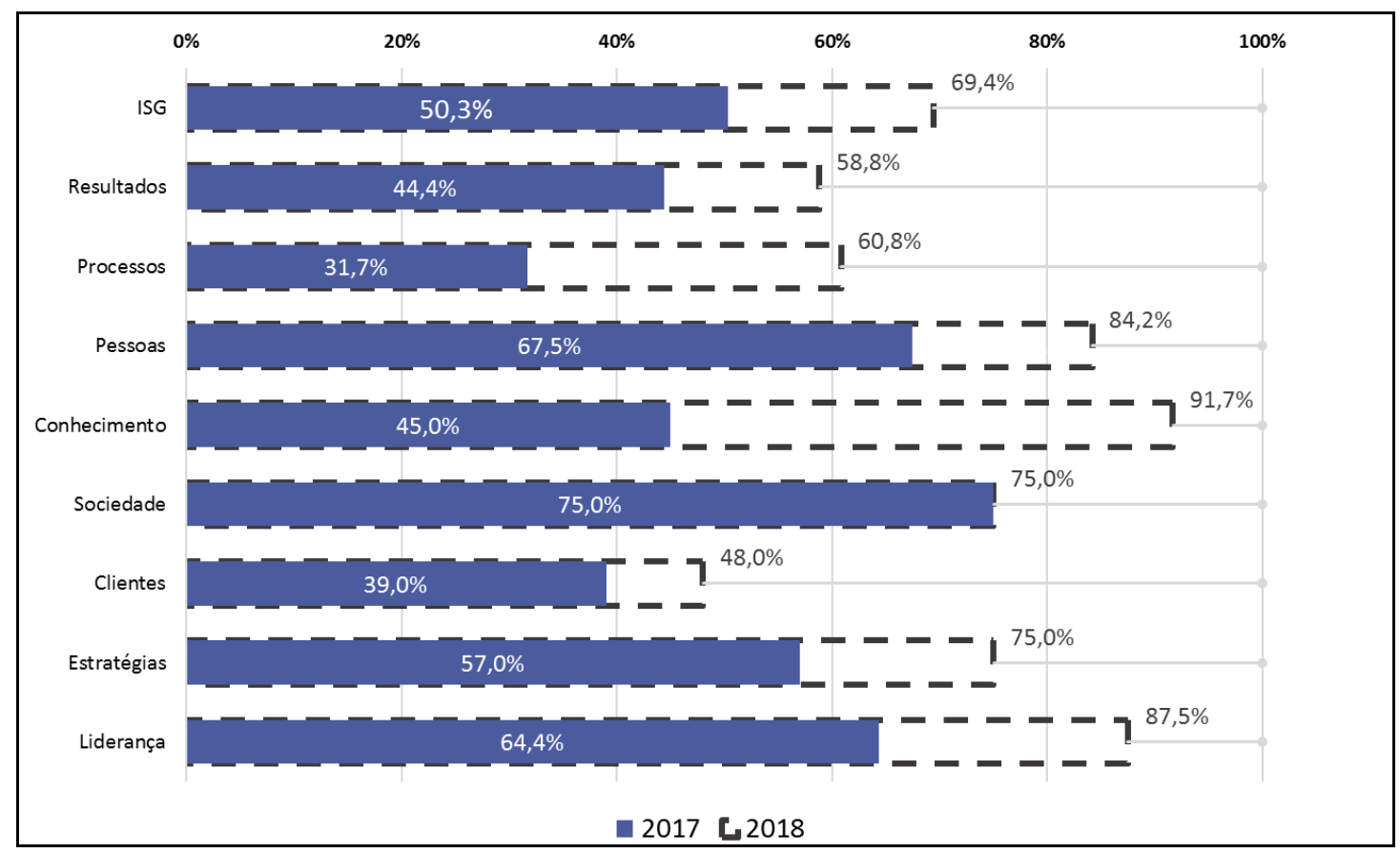

Fonte: SESCOOP/PR (2019)

Observa-se que a cooperativa teve um salto de 23,7 pontos no bloco Governança e 19,1 no bloco de Gestão, em comparação ao ano de 2017. O Gráfico 2 demonstra como a execução do plano de ação traçado no ano anterior foi importante para a Cooperativa melhorar seu desempenho no Bloco de Gestão e seus critérios. Com o diagnóstico gerado pelos instrumentos de autoavaliação do 
PDGC, foram identificadas e priorizadas as oportunidades de melhoria que resultaram na implementação de padrões para controlar os processos da cooperativa, no início do processo de seleção de fornecedores com base em análise de desempenho e na promoção do desenvolvimento dos cooperados. Ademais, observou-se também uma melhoria nos processos gerenciais e uma melhor interação dos dirigentes com os colaboradores.

\section{Considerações Finais}

A partir do estudo do caso da Frísia Cooperativa Agroindustrial, percebe-se que a metodologia desenvolvida pelo Sistema Cooperativista Brasileiro, adaptada do Modelo de Excelência da Gestão ${ }^{\circledast}$ (MEG) da Fundação Nacional da Qualidade (FNQ), aplica-se na cooperativa. Verificou-se a importância do envolvimento da alta direção e da construção compartilhada dos planos de melhoria da gestão.

De acordo com os relatos das partes envolvidas no programa, fica evidente a necessidade de trabalhar com as pessoas, dando-lhes autonomia e responsabilidade, para a construção conjunta. Percebe-se que os resultados alcançados durante os dois anos de projeto estão impactando e adequando a cultura organizacional da Frísia Cooperativa Agroindustrial, que tem mais de 93 anos de história.

O PEGFrísia é um programa de longo prazo que proporciona ganhos diário, especialmente de eficiência de resultado. Por isso é importante manter as pessoas engajadas, pois ainda há um longo caminho a percorrer. A cooperativa entende que a construção da governança ainda está no caminho para se tornar cada vez mais compartilhada e menos segmentada.A participação da alta direção será sempre reforçada, pois além do apoio irrestrito ela proporciona aos executores, também contribui no processo decisório, no processo de gestão, no incentivo, no discurso, na divulgação e valorização das práticas de gestão em excelência em andamento e desenvolvimento, assim como na promoção do Programa de Excelência na Cooperativa, para se obter o engajamento de todos os colaboradores, em todos os níveis e setores da Frísia.

O relato da experiência da Frísia na sua busca por melhoria contínua da estrutura de governança e gestão mostra que a diminuição da assimetria de informações entre as partes interessadas de uma firma tem efeitos práticos. O desafio de ajustar os processos da cooperativa para conciliar interesses de cooperados, gestores profissionais, conselheiros e colaboradores não é trivial, mas é o que torna a organização capaz de se adaptar ao contexto de competição em que ela está inserida. Certamente, um dos melhores indicadores de efetividade de uma empresa, acima até mesmo de indicadores econômico-financeiros, é a sua longevidade. Nenhuma organização passa por diferentes gerações e se mantém relevante por acaso. É necessário que exista uma preocupação constante dentro da estrutura de governança com a capacidade de atender os agentes que interagem em torno e dentro da organização.

Ademais, os resultados deste trabalho demonstram a existência de um vasto campo para estudo. Dentre as sugestões para futuras pesquisas, destaca-se a necessidade de se explorar com mais profundidade o Programa de Excelência da Gestão - PEGCOOP. Além da Frísia, outras cooperativas participam do programa, o que abre espaço para a realização de estudos comparativos, que trarão uma robustez maior ao método estabelecido pelo programa, permitindo o seu aperfeiçoamento.

\section{Referências}

ACI. ALIANÇA COOPERATIVA INTERNACIONAL. Plano de ação para uma década cooperativa. Janeiro de 2013, p. 12.

BOAS, G.A.R.V.; COSTA, H.G. Análise comparativa de prêmios de excelência em gestão. VII Encontro Nacional de Excelência em Gestão, Rio de Janeiro, 2011.

COASE, R. H. The nature of the firm. Economica, v. 4, n. 16, p. 386-405, 1937. 
BRASIL. Lei n. 5.764, de 16 de dezembro de 1971. Define a Política Nacional de Cooperativismo, institui o regime jurídico das sociedades cooperativas, e dá outras providências. Diário Oficial da União. Brasília, DF, 1971.

FRÍSIA. História. Disponível em: <http://www.frisia.coop.br/pt-BR/Paginas/historia.aspx>. Acesso em 27 mai 2019.

FRÍSIA. Relatório Anual 2018. Disponível em: < http://www.frisia.coop.br/ptBR/cooperativa/Paginas/relatorio-anual.aspx>. Acesso em 13 nov. 2019.

IBGC. INSTITUTO BRASILEIRO DE GOVERNANÇA CORPORATIVA. Código das melhores práticas de governança corporativa. 5.ed. / Instituto Brasileiro de Governança Corporativa. - São Paulo, SP, 2015, 108p.

JENSEN, M. C.; MECKLING, W. H. Theory of the firm: Managerial behavior, agency costs and ownership structure. Journal of financial economics, 3(4), 305-36o, 1976.

MARQUES, M. C. C. Aplicação dos princípios da governança corporativa ao sector público. Rev. Adm. Contemp., Curitiba, v. 11, n. 2, p. 11-26, 2007. Disponível em <http://ref.scielo.org/4hfsc8>. Acesso em o6 Jun 2019.

NORTH, D. C. Institutions, transaction costs and economic growth. Economic inquiry, v. 25, n. 3, p. $419-428,1987$.

PAGLIUSO, A. T.; CARDOSO, R.; SPIEGEL, T. Gestão organizacional: o desafio da construção do modelo de gestão. Instituto Chiavenato (org.). São Paulo: Saraiva, 2010.

PDGC. PROGRAMA DE DESENVOLVIMENTODA GESTÃO DAS COOPERATIVAS. Disponível em: http://www.pdgc.somoscooperativismo.coop.br/. Acesso em o6 jun 2019

SESCOOP. SERVIÇO NACIONAL DE APRENDIZAGEM DO COOPERATIVISMO. Programa de Desenvolvimento da Gestão das Cooperativas. Disponível em: http://pdgc.somoscooperativismo.coop.br. Acesso em o6 jun 2019a.

SESCOOP. SERVIÇO NACIONAL DE APRENDIZAGEM DO COOPERATIVISMO. Compêndio de Boas Práticas de Gestão e Governança: ciclo 2017-2018. Disponível em: https://www.ocb.org.br/publicacao/17/compendio-de-boas-praticas-de-gestao-e-governanca. Acesso em 06 jun 2019b.

SOUZA, J. R. M. Análise da Validade do Programa de Desenvolvimento da Gestão das Cooperativas PDGC. (Dissertação de Mestrado) Pontifícia Universidade Católica do Paraná. Programa de PósGraduação em Gestão de Cooperativas. Curitiba, 2019.

VALOR ECONÔMICO. Valorıoo - 1000 Maiores Empresas, Edição 2019. Disponível em https://www.valor.com.br/valor10oo/2019. Acesso em 18 nov 2019.

WILLIAMSON, O. E. The economic institutions of capitalism. New York: Free Press, 1985.

ZANELLA, T. (Coord.). Manual de boas práticas de governança cooperativa. Brasília: Sistema OCB, 2015, $44 \mathrm{P}$. 